\title{
Los ferrocarriles de la República de Honduras*
}

\author{
Marcela Alejandra García \\ Instituto Universitario \\ Ortega y Gasset, Madrid
}

\begin{abstract}
El desarrollo ferroviario de Honduras respondió, ante todo, a las aspiraciones y necesidades del capital extranjero, fundamentalmente norteamericano. El descubrimiento del oro en California, primero, planteó el interés por abrir vías de comunicación en Centroamérica que comunicasen el Océano Atlántico y el Pacífico. La explotación del banano, después, implicó la explotación de una serie de líneas de ferrocarril que aseguraron el abastecimiento de este producto en el mercado norteamericano.

La intención de este trabajo es mostrar la forma en que el desarrollo ferroviario hondureño dependió de las oscilaciones del negocio bananero. Como medio de transporte, adoleció prácticamente de efectos multiplicadores sobre el desarrollo económico y social del país, controlado por las empresas bananeras, concentradas en la región norte del país. Concluido el ciclo alcista de las economías exportadoras y, enfrentado a la competencia de nuevos medios de transporte y a la relativa diversificación económica de la segunda mitad del siglo XX en el marco del Mercado Común Centroamericano, se verá sumido en una crisis de carácter estructural que explica su lamentable estado actual.
\end{abstract}

\section{Introducción}

Las intensas guerras civiles que recorrieron los primeros años de vida independiente de Honduras y la extrema vulnerabilidad de sus sectores dominantes aceleraron la desestructuración de la débil organización económica heredada de los tiempos coloniales. Tenues proyectos para fomentar una producción conforme a los requerimientos del mercado internacional no lograron consolidarse y, al promediar el siglo XIX, la pequeña nación centroamericana se encontraba fragmentada en diversas economías regionales escasamente vinculadas entre sí. El cultivo del tabaco, la ganadería y la minería no lograron convertirse en actividades

* El presente trabajo es resultado de la investigación emprendida por la Fundación de Ferrocarriles Españoles entre 1990 y 1992 en el marco del "Proyecto Los ferrocarriles latinoamericanos: ayer, hoy y mañana” del Proyecto Libertadores. El objetivo de la misma fue elaborar un estado de la cuestión sobre el tema para cada uno de los países latinoamericanos, completándolo con el análisis de algunas fuentes. Participaron en él Carmen Aycart, Angel Rodríguez (Argentina, Uruguay y Brasil), Francisco Polo (Ecuador y Chile), Juan Carlos Sola (México y Guatemala), Antonio Santamaría (Cuba, República Dominicana, Venezuela, Nicaragua y Puerto Rico), Mercedes García (Bolivia, Panamá y Paraguay), Antonio Sanz (El Salvador), Beatriz Vitar (Colombia y Perú) y Marcela García (Honduras y Costa Rica). 
lo suficientemente significativas como para justificar una sólida economía de exportación. La economía hondureña, sumida en la miseria, se orientó al abastecimiento de un raquítico mercado local, cuando no a la subsistencia.

El aislamiento y la pobreza de Honduras no fueron ajenos al obstáculo de su propia configuración geográfica que, sin lugar a dudas, desempeñó un papel condicionante en el desarrollo histórico y económico del país. Las cadenas de montañas, que separan los valles del interior de las tierras bajas costeras, constituyeron un freno para numerosos intentos de promoción económica. ${ }^{1}$ Los escollos del infortunado paisaje para el desarrollo de las comunicaciones fueron uno de los principales factores de impedimento para la formación de un mercado nacional. El transporte, sumamente precario, entre las distintas localidades resultaba demasiado elevado y escasamente rentable en términos económicos.

En el último tercio del siglo XIX, los preceptos liberales que inspiraron las políticas del presidente guatemalteco Justo Rufino Barrios se extendieron a la vecina Honduras. Frente a una situación económica desastrosa, el objetivo prioritario del gobierno de Marco Aurelio Soto, fue promover un desarrollo económico continuo, basado en la producción que consolidase una economía de exportación que definitivamente vinculara a Honduras con los circuitos del mercado internacional. A pesar del incentivo de cultivos de café, caña de azúcar, tabaco y cacao, para finales del siglo XIX, Honduras apenas había logrado asegurar el mínimo de producción agrícola para el mercado interno. Mayores éxitos se alcanzaron en la promoción de la industria minera.

$\mathrm{Al}$ amparo del proyecto liberal y con amplias concesiones gubernamentales, la inversión extranjera fue el principal motor para reactivar la producción de oro y plata de Honduras. La empresa minera Rosario Mining Co., que se organizó en New York en 1879, estuvo en la vanguardia del negocio minero, restando condiciones de competencia a los productores nacionales. Si bien el crecimiento sostenido de la industria minera permitió un relativo incremento de ingresos al estado hondureño, éstos no se tradujeron en firmes proyectos para superar las dificultades de las comunicaciones. El servicio de transportes entre la capital y las minas continuaba efectúandose, a finales de siglo, a lomos de mula, y cuando la pro-

1 Ver Lasserre, Guy: América Media, Barcelona, 1976, págs. 193-208; Yankkelevich, Pablo: Honduras. América Latina. Una historia breve, 1988, págs. 15-19; Pérez Brignoli, Héctor: Breve historia de Centroamérica, Madrid, 1988, págs. 19-34. 
ducción minera llegaba a Tegucigalpa, se cargaba en carretas con dirección al Golfo de Fonseca para su exportación.

Esta relativa expansión económica se conjugó con la acentuada política de expansión de los Estados Unidos en la región, iniciada años antes y proyectada en los incentivos para la construcción de un ferrocarril interoceánico. No obstante, lejos de la intención extranjera estaba la consecución de un proyecto de articular las comunicaciones ferroviarias desde una perspectiva de integración nacional. Desde finales del siglo XIX, Honduras comenzó a desarrollar una floreciente industria frutera que fue pronto objeto de grandes inversiones norteamericanas. ${ }^{2}$ El crecimiento espectacular de esta industria hasta la década de 1930 derivó en la formación de un enclave bananero en el litoral atlántico hondureño, que convirtió al estado en una especie de ente administrativo del emporio frutero. Mediante una excesiva política de concesiones estatales, el desarrollo ferroviario de Honduras quedó aunado, pues, al beneficio de las compañías nortamericanas que lograron expandir sus negocios alrededor del banano: la Cuyamel Fruit Co., los Vaccaro Brothers Co. - futura Standard Fruit Co. - y la United Fruit Co. — que adquirió la supremacía y monopolio del negocio trás la crisis de $1930 .^{3}$

\section{El marco institucional}

\section{La política ferroviaria}

El proyecto inicial de construcción de un ferrocarril que uniese las costas del Océano Atlántico con las propias del Pacífico a través del territorio hondureño obedeció al descubrimiento de oro en California en 1848. Las aspiraciones expansionistas de los Estados Unidos en la región centroamericana se tradujeron en el interés por promover la construcción de un paso interoceánico alternativo a la ruta del Cabo de Hornos para conectar con los centros financieros de la costa este norteamericana. En 1850 nació el proyecto de construir un ferrocarril desde Puerto Cortés hasta el Golfo

2 Kepner, Charles D. y Soothil, J.: El imperio del banano, Buenos Aires, 1957, pág. 107.

3 El conflicto bananero más acérrimo se produjo entre la Cuyamel y la United y llegó incluso a tener importantes consecuencias políticas para el país y a provocar situaciones de enfrentamiento entre Guatemala y Honduras. Véase Posas, Mario: La construcción del sector público y del Estado Nacional en Honduras: 1876-1979, Tegucigalpa, 1983, pág. 240. 
de Fonseca, con buen recibimiento por parte de los gobernantes hondureños. La inauguración de un ferrocarril transcontinental en los Estados Unidos en 1869 y la construcción de un paso interoceánico a través de Panamá, sumados a una serie de problemas financieros, desvalorizaron la construcción del proyectado ferrocarril interoceánico hondureño.

La administración liberal del último tercio del siglo XIX permitió reestructurar la Hacienda pública y, con mayores recursos, el Estado emprendió obras de infraestructura económica y social prioritarias para el país. Con el propósito de superar las dificultades del mal estado de los caminos y del elevado costo de los transportes, que provocaban un extremado aislamiento e independencia de los mercados locales, el gobierno liberal puso en marcha distintos trabajos de reconstrucción y ampliación de caminos bajo la dirección de la Secretaría de Fomento. ${ }^{4}$

Uno de los logros más importantes del gobierno liberal fue, sin embargo, la construcción e inicio de la explotación del Ferrocarril Nacional entre Puerto Cortés y Pimienta en 1892, tramo hasta entonces frustrado del proyectado ferrocarril interoceánico. En los primeros años de la década de 1870, el gobierno recuperó la vía que estaba en manos de concesionarios extranjeros y, haciendo frente a la costosa reparación, logró unir San Pedro Sula con Puerto Cortés, generando con esta obra un gran impulso al movimiento comercial de la costa norte del país.

Especial papel jugó el estado hondureño en las concesiones para la construcción de las vías férreas, sobre todo las relacionadas exclusivamente acorde con los intereses de las compañías extranjeras especializadas en el negocio bananero. El gobierno otorgó concesiones para la construcción de los ferrocarriles a empresarios que eran, en general, de origen norteamericano y británico. Casi todos ellos recibieron el control total de las líneas por períodos que oscilaban entre 60 y 99 años, a partir de cuando el ferrocarril pasaba a ser controlado por el Estado. Como incentivos a los constructores, el Estado solía ofrecer tierras o subsidios en metálico e incluso porcentajes de los beneficios del ferrocarril en sus primeros años de explotación.

El concesionario tenía, también, derecho a la libre utilización de los productos nacionales. Generalmente se le eximía de las tasas de importa-

4 Para más detalles de la evolución de los programas de incentivo de las comunicaciones ver: Molina Chocano, Guillermo: Estado liberal y desarrollo capitalista en Honduras, Tegucigalpa, 1976, págs. 89-94. 
ción de los productos necesarios para su construcción, para el mantenimiento de las instalaciones, para la contratación de la mano de obra y, a veces, se resolvía no establecer impuestos sobre los ferrocarriles. Como contrapartida, el constructor, o la empresa constructora, debía entregar una cantidad de dinero en concepto de garantía de cumplimiento de las claúsulas de la concesión. ${ }^{5} \mathrm{Si}$ bien las concesiones del estado hondureño a las compañías bananeras para la construcción de los ferrocarriles desde sus centros de producción hasta los puertos caribeños eran, en términos generales, en extremo generosas, han pasado por tres fases sucesivas. ${ }^{6}$ En un comienzo, la joven nación hondureña, deslumbrada por los beneficios de los valiosos ferrocarriles y del potencial desarrollo industrial, ayudó dispuestamente a la reciente industria bananera. El período intermedio fue de gran prosperidad y progreso para las compañías, aunque también de mucha desilusión para el gobierno. Por ello, hacia 1895 el gobierno promulgó una Ley Agraria, estipulando que las concesiones de tierra se harían en lotes alternados para impedir que las compañías ejercieran un control completo sobre la región. No obstante, éstas se las ingeniaron para comprar los terrenos que, en principio, no les habían sido concedidos. ${ }^{7}$

\section{Cuadro 1. CONCESIONES FERROVIARIAS OTORGADAS PARA EL ESTABLECIMIENTO DE FERROCARRILES EN HONDURAS}

Años $N .^{o}$ de concesiones

Ferrocarril nacional

Ferrocarriles privados

\begin{tabular}{lc}
\hline $1850-60$ & 2 \\
$1860-70$ & 2 \\
$1870-80$ & 2 \\
$1880-90$ & 2 \\
$1890-00$ & 3 \\
$1900-10$ & 1 \\
$1910-20$ & 1 \\
& \\
\multicolumn{2}{c}{5 Ross, Delmer G.: The Construction of the Railroads of Central America, California, Santa } \\
Bárbara, 1979, págs. 457-459. \\
7 Kepner, Ch. y Soothil, J.: El imperio ...., pág. 163. \\
7 Las discusiones entre el gobierno y las compañías bananeras sobre el problema de los lotes \\
alternados puede verse en: Ibídem, pág. 125.
\end{tabular}

Tomo LIII, 1, 1996 
A partir de la década del 1920 la actitud del gobierno se modificó y fueron rechazadas varias concesiones. No obstante, después de la crisis de 1930 las compañías obtuvieron nuevos beneficios. El gobierno aceptó pagos pequeños, pero inmediatos, a la Hacienda nacional antes que resignarse a cumplir promesas impagables o leyes infringidas.

\section{Cuadro 2. EVOLUCIÓN DEL KILOMETRAJE EN LOS FERROCARRILES DE HONDURAS}

\begin{tabular}{cccc} 
Años & Total kms. & FF.CC. públicos kms. & \% del total \\
\hline 1870 & 59 & 59 & 100 \\
1880 & 92 & 92 & 100 \\
1890 & 92 & 92 & 100 \\
1900 & 92 & 92 & 100 \\
1910 & 114 & 92 & 81 \\
1920 & 230 & 106 & 46 \\
1930 & 1.019 & 106 & 9 \\
1940 & 1.322 & 106 & 8 \\
1950 & 879 & 106 & 12 \\
1960 & 1.302 & 136 & 10 \\
1970 & 1.012 & 136 & 13 \\
1980 & 666 & 136 & 20 \\
1990 & 666 & 463 & 69
\end{tabular}

El cuadro 1 permite tener una perspectiva global de las concesiones ferroviarias otorgadas por el estado hondureño. Los beneficios concedidos a los intereses privados, traducidos en el alto número de contratas para la construcción ferroviaria en veinte años, explican la funcionalidad económica del estado hondureño como un enclave dominado por intereses extranacionales. Gestor y vigilante del desarrollo ferroviario de las compañías bananeras, el estado hondureño poco pudo hacer para articular una red nacional de servicio público o emprender reformas cruciales que supusieran la nacionalización de las líneas.

En los últimos años, se ha producido, sin embargo, un proceso inverso. En 1984, la empresa pública ferroviaria de Honduras se hizo cargo de la administración de uno de los ferrocarriles que recorrían la región 
nor-occidental de Honduras. Esta ampliación de las obligaciones empresariales implicó una variación sustancial en la longitud del ferrocarril público (cuadro 2).

\section{El marco empresarial}

\section{El Ferrocarril Nacional de Honduras}

Las obras del proyectado ferrocarril comenzaron en 1866 al amparo de sucesivas concesiones a empresarios particulares (cuadro 1). Se construiría en tres secciones; la primera, desde Puerto Cortés a Santiago (unos $85 \mathrm{kms}$.); la segunda, desde Santiago a Comayagua (de $136 \mathrm{kms}$.) y la última, desde Comayagua hasta el Golfo de Fonseca (de otros $148 \mathrm{kms}$.). El primer contrato para su construcción data de 1853, otorgado al representante de los Estados Unidos en Centroamérica, Ephrain Squire. Las dificultades financieras fueron rápidamente percibidas, lo que obligó al gobierno hondureño a buscar capital europeo — sobre todo inglés- para continuar con su construcción. Hacia 1869 el ferrocarril estaba operando desde Puerto Cortés a San Pedro Sula y habían sido construidos 91 kms. de vía. Sin embargo, la falta de capitales obligó a la empresa concesionaria a parar la obra en 1873, y el Estado tuvo que hacerse cargo de su continuación. La prolongación del ferrocarril hasta La Pimienta fue lo máximo que el estado hondureño pudo asumir. ${ }^{8}$

Luego de varias concesiones a empresas de capital norteamericano sin demasiado éxito, el ferrocarril interoceánico volvía a ser asumido por el gobierno en 1903, y se denominó Ferrocarril Nacional de Honduras. Otras decepcionantes concesiones acabaron en un nuevo control del ferrocarril por el gobierno entre 1912 y 1920, período en el cual se prolongó hasta Potrerillos, totalizando unos $96 \mathrm{kms}$.

Los negativos rendimientos del ferrocarril obligaron al estado hondureño a transferir la explotación a los intereses privados que preponderaban en el país, aunque sin perder su propiedad. Hacia 1920, el ferrocarril fue arrendado a la Compañía Agrícola de Sula, una subsidiaria de la Cuyamel Fruit Co. Por entonces se construyeron los ramales a Choloma y Villa Estera, conformando una totalidad de 106 kms. de extensión.

8 Molina Chocano, G.: Estado liberal ..., págs. 91-92. 
Como las obligaciones estipuladas en el contrato de arrendamiento a la Compañía Agrícola de Sula poco se cumplieron, el gobierno hondureño, en 1935 concedió la administración del Ferrocarril a la Tela Railway Co., empresa vinculada con la United Fruit Co. y propietaria de otro ferrocarril que recorre la costa norte de Honduras. Bajo su administración se construyeron los últimos $30 \mathrm{kms}$. de un ramal desde Potrerillos a Guanacaste en 1953, además de otros "tramos clandestinos" hacia plantaciones de la compañía bananera no autorizados por el gobierno de Honduras.

Según consta en los archivos de INECO S.A., el gobierno hondureño retomó la administración del ferrocarril en 1958 cuando constituyó el Ferrocarril Nacional de Honduras en el actual Valle de Sula. ${ }^{9}$

La empresa pública amplió sus funciones con la incorporación del Standard Railway Co. en 1984. En efecto, a la recesión del negocio bananero desde la década de 1970, se le sumó las desastrosas consecuencias que causó el huracán Fifí en 1974 en la región nor-oriental de Honduras. El Standard Railway Co., que recorría la zona perjudicada, fue prácticamente abandonado. La empresa decidió rehusar la contrata de explotación del ferrocarril que duraba hasta el año 2009 y pasó a ser administrado por la empresa pública ferroviaria de Honduras. ${ }^{10}$

\section{Los ferrocarriles bananeros}

La ausencia de un sistema de comunicaciones limitaba el desarrollo de las compañías bananeras norteamericanas que desde finales del siglo XIX se habían instalado en la costa norte de Honduras. Producto de las amplias concesiones del estado hondureño a empresarios particulares, los ferrocarriles bananeros se construyeron en las tierras bajas del norte de Honduras, sin otra finalidad que transportar los racimos de bananos desde las plantaciones del interior hacia los puertos del Caribe para su exportación a los Estados Unidos. Si bien la mayoría de los ferrocarriles hondureños fueron construidos al calor de los intereses del transporte bananero, no pueden ser definidos como esencialmente industriales, sino más bien semi- industriales, ya que una vez en explotación realizaban tráfico de mercancías y pasajeros. ${ }^{11}$

9 INECO, S.A.: Estudio de prefactibilidad del plan maestro de la red ferroviaria centroamericana, Anejos II, Madrid, 1992, pág. 1.

10 Ibídem, pág. 5.

11 Ross, Delmer G.: Visionaries and Swindlers: the Development of the Railways of Honduras, Mobile, 1975, pág. 83. 
Cuadro 3. EVOLUCIÓN DEL KILOMETRAJE DE LOS FERROCARRILES PRIVADOS DE HONDURAS Y EL ORIGEN DEL CAPITAL

\begin{tabular}{|c|c|c|c|c|c|c|c|}
\hline \multirow[t]{3}{*}{ Años } & \multirow{3}{*}{$\begin{array}{c}\text { Total kms. } \\
\quad \text { red }\end{array}$} & \multirow{3}{*}{$\begin{array}{l}\text { FF.CC. } \\
\text { privados }\end{array}$} & \multirow{3}{*}{$\begin{array}{l}\text { Kms. \% } \\
\text { del total }\end{array}$} & \multicolumn{4}{|c|}{ Origen del capital } \\
\hline & & & & & & & \\
\hline & & & & kms. & $\%$ & kms. & $\%$ \\
\hline 1870 & 59 & - & - & - & - & - & - \\
\hline 1880 & 92 & - & - & - & - & - & - \\
\hline 1890 & 92 & - & - & & & & \\
\hline 1900 & 92 & - & - & & & & \\
\hline 1910 & 114 & 22 & 19 & & & 22 & 100 \\
\hline 1920 & 230 & 124 & 54 & & & 124 & 100 \\
\hline 1930 & 1.019 & 913 & 90 & & & 913 & 100 \\
\hline 1940 & 1.322 & 1.216 & 91 & & & 1.216 & 100 \\
\hline 1950 & 879 & 773 & 87 & & & 773 & 100 \\
\hline 1960 & 1.302 & 1.166 & 90 & & & 1.166 & 100 \\
\hline 1970 & 1.302 & 1.166 & 90 & & & 1.166 & 100 \\
\hline 1980 & 666 & 530 & 79 & & & 530 & 100 \\
\hline 1990 & 666 & 203 & 30 & & & 203 & 100 \\
\hline
\end{tabular}

Ferrocarril y compañías bananeras formaron en Honduras un binomio inseparable. La rápida expansión de la industria bananera en la región fue en gran parte resultado de la apertura de nuevas vías de comercialización para los frutos que incentivaron los ferrocarriles. Las cifras especificadas en el cuadro 3 indican por sí solas el extraordinario crecimiento de los ferrocarriles privados en Honduras desde el comienzo del siglo XX.

La construcción de la primera línea de ferrocarril bananero, con una trocha standard de $1.06 \mathrm{~ms}$., fue emprendida en 1902 por W. F. Streicht entre Cuyamel y Veracruz. En 1914, la línea ya tenía 31 kms. y llegaba hasta Omoa. Separada de la línea principal del ferrocarril, en 1918 el Estado hondureño le permitió a la empresa iniciar la construcción de un ferrocarril entre Baracoa y Búfalo -más conocido como Ramal de Ulúa. ${ }^{12}$ Los $64 \mathrm{kms}$. de este tramo comenzaron a operar en 1921, mientras que en 1923 la línea principal del ferrocarril de la Cuyamel Company se prolongaba hasta sus propias plantaciones de cacao, teniendo una extensión de $76 \mathrm{kms}$. Este ferrocarril exclusivamente industrial, ya que su funcionalidad

12 Long, Rodney: Railways of Central America and the West Indies, Washington, 1925, pág. 64. 
no era otra que transportar de la forma más rápida y segura la producción bananera desde sus plantaciones a la costa norte hondureña, dejó de ser útil a comienzos de la década de 1930. En efecto, cuando la industria bananera ya no era rentable en la región, las vías ferroviarias fueron reemplazadas por carreteras; el Ramal de Ulúa se fusionó en 1935 con la Tela Railway Co. (cuadro 4).

En 1905 se inició la construcción de otro ferrocarril bananero en un lugar denominado Salado Bar bajo la dirección de los Vaccaro Brothers. En 1908 la línea llegaba hasta La Ceiba conn una extensión de 13 kms. Durante las dos décadas siguientes se construyeron otros ramales hacia puntos de interés de la Standard Railway and Steamship Co., empresa que asumió los compromisos financieros de la Vaccaro Brothers hacia 1924. Fue el único ferrocarril hondureño construido con una trocha de $0,91 \mathrm{~ms}$. y su máxima extensión, $540 \mathrm{kms}$. -incluyendo los ramales a las plantaciones- la alcanzó en 1952. Sin embargo, para entonces, apenas $255 \mathrm{kms}$. eran utilizados para el transporte de mercancías privadas y de pasajeros; el transporte de la producción bananera que controlaba la Standard en la región que atravesaba el ferrocarril constituía las dos terceras partes del tráfico ferroviario. Hasta hace apenas unos años el puerto de La Ceiba - de sustancial importancia para el comercio de exportación e importación del país- y sus alrededores eran una de las más prósperas áreas industriales de Honduras; bajo el control de la Standard Railway Co. una amplia gama de productos fabricados en la región se destinaban al mercado hondureño. Las últimas dos décadas fueron desastrosas para la zona por los daños irreparables que provocó el huracán en 1974. El puerto de La Ceiba cedió su importancia al Puerto de Castilla y el foco de recuperación económica se trasladó hacia las costas nor-orientales. Las vías ferroviarias fueron en gran parte desvastadas, hasta tal punto que la Standard decidió diez años después abandonar su concesión para la explotación del ferrocarril.

El ferrocarril de la Tela Railway Co., compañía unida a los intereses financieros de la United Fruit Co., comenzó a operar en 1916. Hacia 1923 la línea se había prolongado unos 282 kms. Su construcción continuó hasta 1953 en que la compañía tenía una red de $626 \mathrm{kms}$., constituyendo la mayor extensión ferroviaria industrial en Centroamérica, aunque, al igual que el ferrocarril de la Standard Co., también se utilizaba para el transporte de pasajeros. Posee dos líneas principales: la primera, entre Tela —en la costa atlántica- - y Progreso —en el interior - tiene $90 \mathrm{kms}$., con dos importantes ramales de 12 y $7 \mathrm{kms}$., respectivamente; la segunda es la de 

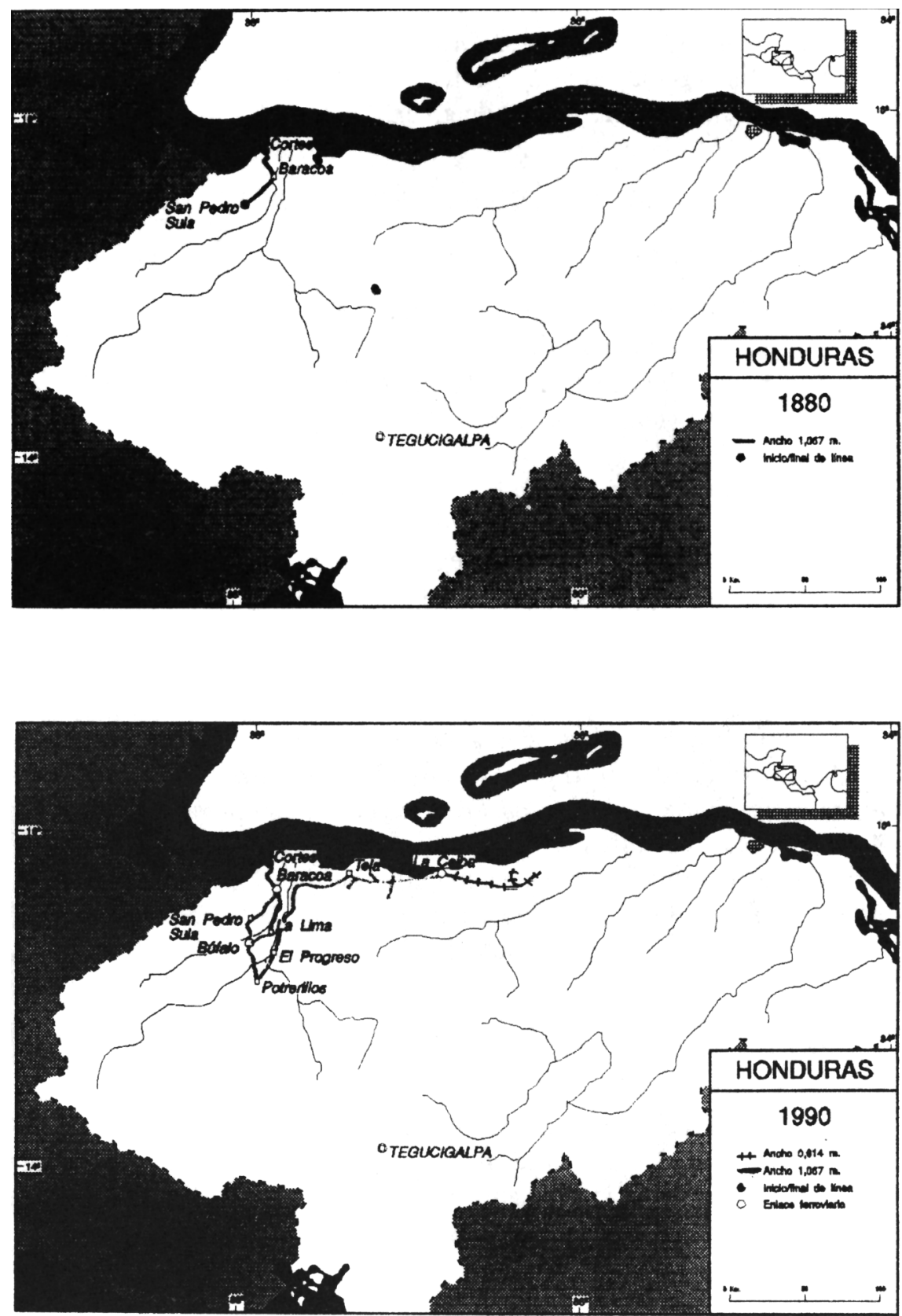
Baracoa-Búfalo, adquirida por la Cuyamel en 1935 y cuya longitud es de $64 \mathrm{kms}$. de línea principal y dos ramales de 21 y 9 kms., respectivamente. En total, hoy en día el ferrocarril opera en $203 \mathrm{kms}^{13}$

\section{Cuadro 4. FUSIONES DE FERROCARRILES}

\begin{tabular}{llc} 
Año & Ferroc. afectados por la fusión & Kms. afectados \\
\hline 1935 & $\begin{array}{l}\text { Ramal de Ulúa de la Cuyamel Fruit Co. } \\
\text { y el Tela Fruit Co. }\end{array}$ & 64 \\
1934 & $\begin{array}{l}\text { Standard Fruit Co. y Ferrocarril } \\
\text { Nacional de Honduras }\end{array}$ & 327
\end{tabular}

Cuando en 1935 la Tela Railway Co. se hizo cargo de la administración del Ferrocarril Nacional de Honduras, las dos empresas, al tener ambas una trocha de 1,067 cms., arreglaron para el uso común de equipos y servicios, responsabilizándose del pago recíproco por el uso de dichos servicios, reparaciones y materiales. La Tela Railway Co. hace uso, asimismo, del tramo del Ferrocarril Nacional entre Baracoa y Puerto Cortés para tener el acceso al puerto comercial más importante de la región. En 1976 finalizó la concesión a la Tela Railway Co., alquilándola posteriormente el gobierno a la misma compañía hasta $1993 .{ }^{14}$

Otro ferrocarril industrial bananero, el Trujillo Railway Co., también empresa subsidiaria de la United Fruit, comenzó a construirse a partir de 1913 en la costa nor-oriental hondureña. Hacia 1936 el ferrocarril llegaba hasta Puerto Castilla y tenía una longitud de $443 \mathrm{kms}$. con numerosos ramales a plantaciones bananeras; sin embargo, desde entonces dejó de operar y sus vías fueron definitivamente levantadas en 1949.

\section{Inversiones en ferrocarriles}

Es difícil precisar la cuantía de los capitales invertidos en la construcción y explotación de los ferrocarriles privados debido al secreto que las compañías mantenían respecto a los ingresos, gastos y rentabilidad económica del negocio bananero en su conjunto. Sin embargo, del cuadro

13 INECO, S.A.: Estudio ..., pág. 6.

14 Ibídem, pág. 1. 
5 puede apreciarse el origen del capital norteamericano en la totalidad de las empresas ferroviarias semi-industriales. En lo que respecta al Ferrocarril Nacional de Honduras, se dispone de alguna información útil para comentar sobre los capitales invertidos para su construcción y puesta en funcionamiento.

Incapacitado el Estado hondureño para llevar a cabo la construcción del Ferrocarril Interoceánico con sus propios recursos, ofreció tierras y exenciones tributarias para aquellos empresarios que invirtiesen en la construcción del ferrocarril. Los potenciales inversores no encontraban rentable la empresa y los problemas financieros para comenzar los trabajos parecían insalvables. Sin embargo, en los últimos años del gobierno conservador se impulsó, a través de sus representantes europeos, la búsqueda de capital para iniciar las obras del ferrocarril. Sucesivos empréstitos fueron firmados con firmas inglesas y francesas como la Bischoffshein y Goldschmidt y la Waring Brothers and MacClandish entre 1867 y $1973 .{ }^{15}$ El Estado especulaba con que una vez finalizado el ferrocarril, los ingresos de su explotación serían suficientes para pagar los préstamos.

A mediados de la década de 1870 , el total de los préstamos alcanzaba la cifra de casi 6.000.000 de libras, pero apenas medio millón había llegado a Honduras para la construcción del ferrocarril. ${ }^{16} \mathrm{Si}$ la situación financiera no era la mejor para afrontar la construcción del ferrocarril, menos lo era la situación política. En medio de un ambiente tenso y faccioso, los fondos reservados para la construcción del ferrocarril eran destinados a cuestiones políticas, acrecentando así la incertidumbre sobre el futuro de la vía. ${ }^{17}$

Cuando el ferrocarril pasó a ser administrado por una empresa subsidiaria de la Cuyamel Fruit Co., ésta le concedió al Estado hondureño, que aún conservaba su propiedad, un préstamo de 1.000 .000 de dólares para completar y reparar la línea. Sin embargo, la compañía, como administradora del ferrocarril, desembolsó más cantidad de dinero que el estipulado en las obligaciones del crédito y mantuvo al ferrocarril continuamente en deuda. Sumado a las restantes deudas que el estado había asumido en los círculos financieros europeos para la puesta en marcha del Ferrocarril

15 Ver Ross, D. G.: The Construction ..., pág. 114, 143-145; Morales, Jorge: "El Ferrocarril Nacional de Honduras: su historia e incidencia sobre el desarrollo económico", en Estudios Sociales Centroamericanos, vol. 1, n. ${ }^{\circ}$ 1, Costa Rica, mayo-agosto de 1972, pág. 120; y Molina Chocano, G.: Estado liberal ..., págs. 102-103.

16 Molina Chocano, G.: Estado liberal ..., pág. 103 y 114.

17 Yankelevich, P.: Honduras ..., págs. 118-120, y Bermúdez, Rubén: El drama del Ferrocarril Nacional de los hondureños, San Pedro Sula, 1928. 
Nacional, esta deuda terminó por agotar el capital de las arcas estatales. Fue en 1954 cuando el Estado logró deshacerse del terrible peso financiero que había sido el proyectado ferrocarril interoceánico hondureño; la totalidad del capital prestado y sus intereses fueron entonces cancelados. ${ }^{18}$

Cuadro 5. PAÍSES DE ORIGEN DEL CAPITAL

Años

Capital norteamericano

N. ${ }^{o}$ empresas

Kms.

1870

1880

1890

1900

1 9

1910

2

22

1920

124

1930

913

1940

1.216

1950

773

1960

1.166

1970

1.166

1980

530

1990

203

\section{Los factores de producción}

\section{La infraestructura}

El desarrollo de la red ferroviaria de Honduras estuvo condicionado por los intereses económicos extranjeros que primaron en el país desde finales del siglo XIX. Son, por tanto, razones de rentabilidad económica las que explican la localización de la totalidad de los ferrocarriles hondureños en la costa norte del país, coincidente con el área de desarrollo de las principales compañías bananeras.

Iniciado el siglo XX, se habían construido apenas $92 \mathrm{kms}$. de ferrocarril (cuadros 6 y 7). En efecto, durante el último tercio del siglo XIX la

18 Morales, J.: “El ferrocarril ...”, pág. 13. 
lenta construcción ferroviaria en Honduras se debió a los problemas de financiamiento que suponía el proyectado Ferrocarril Interoceánico. La línea para servicio público nunca fue completada en su totalidad; el tramo construido no exigió demasiadas obras de infraestructura, más que puentes para el paso del ferrocarril sobre el río Chamelecón y Ulúa.

Cuadro 6. DESARROLLO DE LA RED FERROVIARIA

Quinquenio Kms.red Constr. Construido en \% Kms. $x$ habs. kms.red Quinq. Quinq. anterior $\quad 1000 \quad 1000 \quad x 1000$ km. ${ }^{2}$ hats.

\begin{tabular}{lrrrrrr}
\hline $1866-70$ & 59 & 59 & 100,0 & 0,527 & 397 & 0,149 \\
$1871-75$ & 85 & 26 & 44,1 & 0,759 & 411 & 0,207 \\
$1876-80$ & 92 & 7 & 8,2 & 0,821 & 426 & 0,216 \\
$1881-85$ & 92 & 0 & 0,0 & 0,821 & 441 & 0,209 \\
$1886-90$ & 92 & 0 & 0,0 & 0,821 & 456 & 0,202 \\
$1891-95$ & 92 & 0 & 0,0 & 0,821 & 472 & 0,195 \\
$1896-00$ & 92 & 0 & 0,0 & 0,821 & 490 & 0,188 \\
$1901-05$ & 97 & 5 & 5,4 & 0,866 & 523 & 0,185 \\
$1906-10$ & 109 & 12 & 12,4 & 0,973 & 563 & 0,194 \\
$1911-15$ & 193 & 84 & 77,1 & 1,723 & 607 & 0,318 \\
$1916-20$ & 226 & 33 & 17,1 & 2,018 & 654 & 0,346 \\
$1921-25$ & 733 & 507 & 224,3 & 6,545 & 704 & 1,041 \\
$1926-30$ & 1.019 & 286 & 39,0 & 9,098 & 792 & 1,287 \\
$1931-35$ & 1.019 & 0 & 0,0 & 9,098 & 1.025 & 0,994 \\
$1936-40$ & 1.322 & 303 & 29,7 & 11,804 & 1.144 & 1,156 \\
$1941-45$ & 1.322 & 0 & 0,0 & 11,804 & 1.192 & 1,109 \\
$1946-50$ & 1.145 & -177 & $-13,4$ & 10,223 & 1.327 & 0,863 \\
$1951-55$ & 1.156 & 11 & 1,0 & 10,321 & 1.503 & 0,769 \\
$1956-60$ & 1.302 & 146 & 12,6 & 11,625 & 1.754 & 0,742 \\
$1961-65$ & 1.302 & 0 & 0,0 & 11,625 & 2.153 & 0,605 \\
$1966-70$ & 1.302 & 0 & 0,0 & 11,625 & 2.479 & 0,525 \\
$1971-75$ & 1.175 & -127 & $-9,8$ & 10,491 & 2.901 & 0,405 \\
$1976-80$ & 666 & -509 & $-43,3$ & 5,946 & 3.437 & 0,194 \\
$1981-85$ & 666 & 0 & 0,0 & 5,946 & 4.088 & 0,163 \\
$1985-90$ & 666 & 0 & 0,0 & 5,946 & 4.832 & 0,138
\end{tabular}

Como era de esperar, durante los primeros veinte años del siglo $\mathrm{XX}$, la construcción de ferrocarriles en Honduras obedeció a las prioridades de transporte de la industria bananera. Fue, no obstante, durante toda la déca- 
da de 1920 cuando la construcción ferroviaria cobró un notable impulso, siempre a merced de los intereses privados. Durante el quinquenio 1921-1925 la red había crecido 507 kms. y se había construido un 224,3\% más respecto al quinquenio anterior. Tal significativo crecimiento se debió al especial progreso que realizaron el Standard Railway Co. y el Trujillo Railway Co. en aquellos años. La red continuó ampliándose en el quinquenio 1926-1930, aunque en menores proporciones. Luego de la recesión del 30, se construyeron nuevos tramos ferroviarios; para 1936 la red había alcanzado una longitud de $1.322 \mathrm{kms}$. El Ferrocarril Nacional continuaba con $106 \mathrm{kms}$. de extensión, mientras que los restantes $1.216 \mathrm{kms}$. pertenecían a las empresas bananeras. Para entonces, la red ferroviaria alcanzó su máxima extensión, observable desde su relación con las dimensiones de superficie de Honduras. Si en el quinquenio 1871-1875, estaban en explotación apenas $0.82 \mathrm{kms}$. por $1000 \mathrm{kms} .^{2}$, para el de 1936-1940 la relación se había elevado a $11.80 \mathrm{kms}$.

\section{HONDURAS \\ Longitud de la Red}

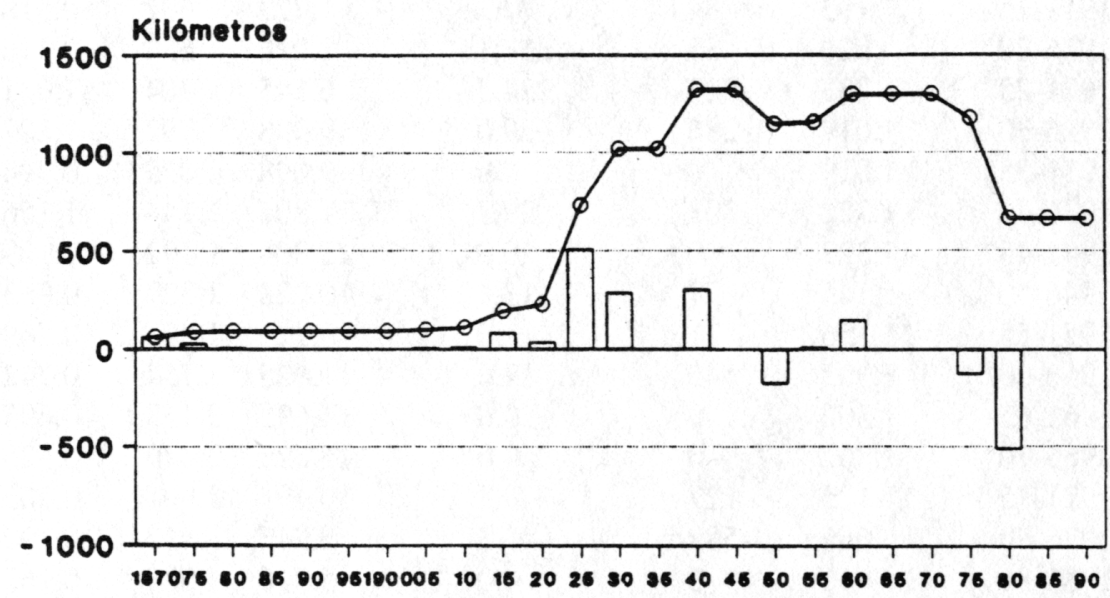

$\square$ Ouinquenie Reumulade

Fuenter Eleberacion propia 
La rápida construcción ferroviaria en la época se completó con importantes obras de infraestructura sobre los ríos Ulúa y Aguán; otros puentes fueron necesarios para que las vías atravesaran los suelos pantanosos que conformaban la región. El ferrocarril de la Tela Railway Co., especialmente, tiene infinidad de puentes sobre los cursos de agua; sólo entre Tela y El Progreso, tramo de 90 kms., existen un total de 126 puentes, lo que significa un puente cada 740 metros. $^{19}$

\section{Cuadro 7. LONGITUD PORCENTUAL DE LOS DIVERSOS FERROCARRILES EN RELACIÓN CON EL TOTAL}

\begin{tabular}{lrrcccc}
$\begin{array}{l}\text { Años term. } \\
\text { en "0" }\end{array}$ & $1 \%$ & $2 \%$ & $3 \%$ & $4 \%$ & $5 \%$ & Total \\
\hline 1870 & 100 & - & - & - & - & 100 \\
1880 & 100 & - & - & - & - & 100 \\
1890 & 100 & - & - & - & - & 100 \\
1900 & 100 & - & - & - & - & 100 \\
1910 & 81 & 8 & 11 & - & - & 100 \\
1920 & 46 & 16 & 38 & - & - & 100 \\
1930 & 10 & 7 & 47 & 28 & 13 & 100 \\
1940 & 8 & (c) & 32 & 26 & 34 & 100 \\
1950 & 12 & & 49 & 39 & (c) & 100 \\
1960 & 10 & & 42 & 48 & & 100 \\
1970 & 10 & & 42 & 48 & & 100 \\
1980 & 20 & & 49 & 31 & & \\
1990 & 70 & & (c) & 30 & &
\end{tabular}

Empresas:

1. Ferrocarril Nacional de Honduras

2. Cuyamel Railway Company

3. Standard Fruit and Steamship Company

4. Tela Railway Company

5. Trujillo Railway Company

(c): cierre de línea

Desde mediados de la década de 1930 hasta entrados los años 40, la declinación de la industria bananera fue el motivo de reducción de la red

19 INECO: Estudio ..., pág. 5. 
ferroviaria hondureña. Debido a los efectos desvastadores de las plagas de Panamá y Sigatoka que se extendieron por entonces entre las plantaciones bananeras, dejaron de utilizarse algunas líneas ferroviarias. A mediados de la década del 30 se abandonaron los $76 \mathrm{kms}$. de línea principal del Cuyamel Railway Co., mientras comenzaban a levantarse las vías del Trujillo Railway Co., cerrado totalmente al tráfico en 1949 (cuadro 8).

Cuadro 8. CIERRES DE FERROCARRILES Y TRAMOS EN HONDURAS

\begin{tabular}{|c|c|c|}
\hline \multirow{3}{*}{$\frac{A \tilde{n} o}{1935\left(^{*}\right)}$} & Ferrocarril & Kms. cerrc \\
\hline & $\begin{array}{l}\text { Cuyamel-Omoa } \\
\text { (tramo principal del }\end{array}$ & \\
\hline & Cuyamel Railway Co.) & 76 \\
\hline 1949 & Trujillo Railway Company & 443 \\
\hline
\end{tabular}

Durante los primeros años de la década de 1950, los buenos rendimientos de las compañías bananeras - relacionados aquellos con producciones alternativas al banano- justificaron un nuevo, aunque tenue, impulso a la construcción ferroviaria. El Ferrocarril Nacional extendió unos $30 \mathrm{kms}$. sus vías hacia plantaciones bananeras, completando unos $136 \mathrm{kms}$. Por tanto, el único ferrocarril hondureño destinado para el servicio público fue construido apenas en la tercera parte de su proyecto original. El trazado principal del Ferrocarril Nacional partía de Puerto Cortés, en la costa atlántica, pasaba por San Pedro Sula para terminar en El Progreso, y conectar con uno de los ramales del Tela Railway Co. La ampliación de las vías de ferrocarril público no alcanzó, sin embargo, la ciudad capital de Tegucigalpa, privándole así de servicio ferroviario. Las empresas Standard Railway y Tela Railway también extendieron su red hacia plantaciones de banano para alcanzar 540 y $626 \mathrm{kms}$. respectivamente. En el segundo quinquenio de la década la red ferroviaria hondureña había crecido un $13 \%$ respecto al quinquenio anterior, conformando una longitud de $1.302 \mathrm{kms}$. Según las observaciones de $\operatorname{Ross}^{20}$ la red era la más amplia respecto a los demás países centroamericanos. Sin embargo, un $90 \%$ de su extensión consistía en líneas ferroviarias operadas por compañías bananeras controladas por la United Fruit Co.

20 Ross, D. G.: Visionaries ..., pág. 83. 
La disminución de la red registrada desde mediados de la década de 1970 obedeció al abandono de varias tramos de las vías de las compañías bananeras. En la actualidad la red tiene unos $666 \mathrm{kms}$., de los cuales un 70\% corresponden al Ferrocarril Nacional de Honduras con su división en dos sectores: el primero, en el Valle de Sula (trazado originario del ferrocarril de $137 \mathrm{kms}$.); y el segundo en La Ceiba (antiguo ferrocarril de la Standard Co., de $327 \mathrm{kms}$.). Los restantes $203 \mathrm{kms}$. corresponden al Tela Railway Co.

Si antes de la fusión con la Standard Railway Co. la trocha del Ferrocarril Nacional era de 1,06 cms., en la actualidad se combina con la de 0,91. En efecto, de los $463 \mathrm{kms}$. del ferrocarril, 233 son de trocha de $1,06 \mathrm{cms}$. (los 137 kms. originarios del Ferrocarril Nacional de Honduras y otros $97 \mathrm{kms}$. del tramo Tela-La Ceiba) y los restantes $230 \mathrm{kms}$. del sector de La Ceiba son de una trocha de $0,91 \mathrm{cms}$. A pesar de los trabajos de reconstrucción y de reparación de la vía del sector de La Ceiba que ha hecho la propia Standard Railway Co. entre 1983 y 1985, ${ }^{21}$ — cambiando incluso la anchura de la trocha, de 0,91 a 1,067 en el tramo Tela-La Ceiba-, el ferrocarril está fuera de servicio desde 1989. ${ }^{22}$ En general, el estado de la vía está en muy malas condiciones, sobre todo la cercana a las cuencas fluviales donde, en época de lluvias, se producen inundaciones que progresivamente desgastan la plataforma, traviesas y rieles, cuyo estado de por sí es deficiente.

\section{Los equipos}

Las fluctuaciones del equipo de transporte estuvieron relacionadas con las etapas de auge y decadencia de la industria bananera. Hasta comienzos de la década de 1930, la adquisición de material motor y remolcado, procedente de Gran Bretaña y, más aún, de los Estados Unidos, evolucionó de forma creciente, sobre todo para las empresas ferroviarias de las compañías bananeras. La recesión de la industria, que se prolongó hasta entrada la década de 1940, provocó asimismo la reducción del parque. Además, siendo la finalidad prioritaria de los ferrocarriles hondureños el transporte de racimos desde los puntos de producción a los de comer-

21 INECO: Estudio ..., pág. 5.

22 Ibídem, pág. 15. 
cialización, desde los inicios de la explotación ferroviaria, los vagones de carga adquirieron un notable predominio sobre los coches de viajeros.

La evolución del parque desde 1950 marca las tendencias predecibles de la lectura de la cifras indicadas. Desde 1950, la progresiva construcción de carreteras en el país significó una seria competencia para el transporte ferroviario. El material viejo y necesario de reparación no estaba en condiciones de competir con el transporte automotor, por tanto se procedió a su modernización. Tanto el número de locomotoras como de material de remolque experimentó un notable crecimiento durante toda la década de 1960, reflejado en la relación de los coeficientes obtenidos en el cuadro 10. La sustitución del vapor por tecnología Diesel en el material de tracción fue por entonces realizada en todos los ferrocarriles hondureños, aunque recayó en su mayoría en las empresas ferroviarias privadas.

Cuadro 9. EQUIPOS DE TRANSPORTE DE LOS FERROCARRILES HONDUREÑOS

\begin{tabular}{cccccr} 
Quinquenio & $N^{\circ}{ }^{o}$ locom. & $N^{*}{ }^{o}$ autom. & $N^{*}{ }^{o}$ coches & $N .^{o}$ vagones & Total \\
\hline $1951-55$ & 53 & - & 51 & 1.853 & 1.957 \\
$1956-60$ & 40 & - & 48 & 1.960 & 2.048 \\
$1961-65$ & 70 & - & 79 & 1.617 & 1.766 \\
$1966-70$ & $74(1)$ & 97 & 76 & 2.407 & 2.655 \\
$1971-75$ & $65(2)$ & 95 & 65 & 1.761 & 1.987 \\
$1976-80$ & 18 & 17 & 90 & 517 & 642 \\
$1981-85$ & 14 & 17 & 16 & 517 & 565 \\
$1986-90$ & 36 & 17 & 16 & 1.564 & 1.633
\end{tabular}

(1) Del total de locomotoras, 20 eran a vapor y 54 Diesel.

(2) Del total, 13 locomotras eran a vapor y 52 Diesel.

El aumento de los automotores, coches de viajeros y vagones de carga estuvo asimismo relacionado con la demanda de servicio de transporte de mercancías y viajeros que generó la incipiente diversificación industrial en la región norte del país. La decadencia económica de la zona desde mediados de la década de 1970 explica la reducción en la oferta de material ferroviario, sobre todo desde el abandono del ferrocarril de la Standard Co. El repunte experimentado en el último quinquenio se explica a partir de la 
reparación de algunos de los equipos ${ }^{23}$ que anteriormente pertenecían a aquella empresa. Si bien la incorporación de los materiales de la antigua Standard Railway Co. acrecentó el parque del Ferrocarril Nacional de Honduras, el mismo es casi un 50\% menor que el de la Tela Railway Co. En la actualidad ambos ferrocarriles tienen 25 locomotoras cada uno, en lo que respecta al material remolcado la diferencia es apreciable: la relación del material remolcado del Tela Railway Co. es de 1.446 unidades contra 827 del Ferrocarril Nacional. ${ }^{24}$

Cuadro 10. EQUIPOS DE TRANSPORTE DE LOS FERROCARRILES HONDUREÑOS (COEFICIENTES)

\begin{tabular}{|c|c|c|c|c|c|c|c|c|c|}
\hline \multirow[t]{2}{*}{ Quinquenio } & \multicolumn{4}{|c|}{ Porcentajes } & \multirow{2}{*}{$\begin{array}{c}\% \\
\text { Total }\end{array}$} & \multirow{2}{*}{$\begin{array}{l}\text { Locom. } \\
x \\
\text { km. vía }\end{array}$} & \multirow{2}{*}{$\begin{array}{c}\text { Coches+ } \\
\text { vagones/ } \\
\text { Locom. }\end{array}$} & \multirow{2}{*}{$\begin{array}{l}\text { Coches+ } \\
\text { vagones/ } \\
x \text { km. vía }\end{array}$} & \multirow{2}{*}{$\begin{array}{c}\text { Coches+ } \\
\text { aut. en } \\
\text { \% vag. }\end{array}$} \\
\hline & Loc. & Aut. & Coch. & Vag. & & & & & \\
\hline $1951-55$ & 2,71 & 2,61 & & 94,96 & 100 & 4,6 & 35,9 & 1,65 & 2,75 \\
\hline $1956-60$ & 1,95 & 2,34 & & 95,70 & 100 & 3,1 & 50,2 & 1,54 & 2,45 \\
\hline $1961-65$ & 3,96 & 4,47 & & 91,56 & 100 & 5,4 & 24,2 & 1,30 & 4,89 \\
\hline $1966-70$ & 2,82 & 3,65 & 2,86 & 90,66 & 100 & 5,8 & 33,1 & 1,91 & 7,19 \\
\hline $1971-75$ & 2,32 & 4,78 & 3,27 & 88,63 & 100 & 5,6 & 27,7 & 1,55 & 9,09 \\
\hline $1976-80$ & 2,80 & 2,65 & 14,02 & 80,53 & 100 & 2,7 & 33,7 & 0,91 & 20,70 \\
\hline $1981-85$ & 2,65 & 3,01 & 2,83 & 91,50 & 100 & 1,6 & 35,5 & 0,58 & 6,38 \\
\hline $1986-90$ & 2,20 & 1,04 & 0,98 & 95,77 & 100 & 5,4 & 43,9 & 2,37 & 2,11 \\
\hline
\end{tabular}

\section{El factor trabajo}

Son escasísimos los datos que se poseen referentes a los trabajadores ferroviarios de Honduras, además los que comentaremos corresponden al Ferrocarril Nacional y son relativamente recientes. Para 1977, su número era de 327, divididos por ocupaciones de la siguiente manera: 43 dedicados a servicios generales, otros 182 a los talleres, y los restantes 102 al transporte. Durante el período 1978-1982, unos 6 trabajadores más se dedicaban a trabajos no especificados.

23 Los principales instalaciones para la reparación y el equipo ferroviario se encuentran en San Pedro Sula y en La Ceiba para el Ferrocarril Nacional de Honduras y en La Lima para el Tela Railway Co. Ibídem, pág. 11.

24 Ibídem, pág. 18. 
En 1992, según cifras de INECO S.A., ${ }^{25}$ eran 528 los empleados del Ferrocarril Nacional de Honduras (321 del sector Valle de Sula y 207 del Sector de la Ceiba) distribuidos en las categorías de administración, tráfico, mantenimiento de material, de vías, Agencia de Aduanas y Seguridad. Dicha plantilla se ha reducido en un $28 \%$ respecto al año 1987 debido fundamentalmente a la inoperatividad del sector de La Ceiba y, con menor importancia, al descenso de la actividad del sector del Valle de Sula. Por otra parte, en la actualidad, el ferrocarril tiene 132 jubilados que cobran el $70 \%$ de su salario, lo que repercute en las cifras económicas de explotación del ferrocarril.

\section{El transporte}

\section{Tráfico de viajeros}

Desde mediados del siglo $\mathrm{XX}$, mermó progresivamente el número de pasajeros que utilizaba el ferrocarril como medio de transporte (cuadro 11), pues el transporte automotor ofreció una alternativa más rápida y económica. A esta tendencia no escapó ni siquiera el Ferrocarril Nacional, superado en el servicio de transporte de pasajeros por el Tela Railway Co.

El tenue crecimiento registrado en el primer quinquenio de la década del 1970 se debió al desarrollo demográfico e industrial del norte de Honduras. El tráfico ferroviario de pasajeros fue uno de los factores que aceleraron el rápido crecimiento de ciudades como San Pedro Sula y La Ceiba.

En la actualidad, los servicios de transporte de pasajeros ofrecidos por los ferrocarriles hondureños comprenden tres trayectos. El primero, de San Pedro Sula a Puerto Cortés, con tres horas de recorrido, de frecuencia diaria y a una velocidad de $20 \mathrm{kms}$./h. El segundo, de Puerto Cortés a Tela, de frecuencia diaria, con duración de 4 horas a una velocidad de $18 \mathrm{kms} . / \mathrm{h}$. El último, Puerto Cortés-Lima, que dura 4 horas, con una frecuencia de 4 veces a la semana a una velocidad de $19 \mathrm{kms} . / \mathrm{h} .{ }^{26}$

25 Ibídem, págs. 13 y 14.

26 Ibídem. 
Cuadro 11. TRANSPORTE DE VIAJEROS

\begin{tabular}{lcccccc} 
Quinqu. & $\begin{array}{c}\text { Viaje } \\
\text { (miles) }\end{array}$ & $\begin{array}{c}\text { Viaje } \\
\text { x hab. }\end{array}$ & $\begin{array}{c}\text { Viaje } \\
\text { x km. vía }\end{array}$ & $\begin{array}{c}\text { Viaje/km. } \\
\text { (millón) }\end{array}$ & $\begin{array}{c}\text { Viaje/km. } \\
\text { /habs. }\end{array}$ & $\begin{array}{c}\text { Viaje/km. } \\
\text { /km. vía }\end{array}$ \\
\hline $1951-55$ & 1.457 & 0,97 & 1,26 & 176 & 0,117 & 0,152 \\
$1956-60$ & 817 & 0,47 & 0,63 & 57 & 0,032 & 0,044 \\
$1961-65$ & 692 & 0,32 & 0,53 & 55 & 0,026 & 0,042 \\
$1966-70$ & 825 & 0,33 & 0,63 & 11 & 0,004 & 0,008 \\
$1971-75$ & 1.040 & 0,36 & 0,89 & 10 & 0,003 & 0,009 \\
$1976-80$ & 156 & 0,05 & 0,23 & 8 & 0,002 & 0,012 \\
$1981-85$ & 160 & 0,04 & 0,24 & 8 & 0,002 & 0,012 \\
$1986-90$ & 163 & 0,03 & 0,24 & 8 & 0,002 & 0,012
\end{tabular}

\section{Transporte de mercancías}

Desde el inicio de la explotación ferroviaria, el banano fue la principal mercancía transportada y su evolución dependió, por tanto, de las fluctuaciones de esa industria. Si bien disponemos de datos seriados a partir de la década de 1950, la tendencia del volumen transportado en los quinquenios anteriores es fácilmente deducible por lo explicado en apartados precedentes.

Después de un ligero descenso de la cantidad de toneladas transportadas en el segundo quinquenio de la década de 1950 y en el primero de la siguiente, su volumen asciende considerablemente durante los quinquenios 1966-1970 y 1971-1976. No sólo la elección del transporte automotor y de aviación explica esta tendencia, sino también los cambios operados en el sector productivo y en la composición del comercio exterior hondureño.

En efecto, desde la década de 1950,el banano ha ido disminuyendo su importancia en términos relativos como principal producto de exportación de Honduras, al tiempo que otros productos como el café, la madera, ganado en pie, carne, minerales y algodón componían casi un $60 \%$ de las exportaciones. ${ }^{27}$ Fueron precisamente las compañías bananeras las que diversificaron sus intereses hacia otras actividades productivas y comerciales alternativas y los ferrocarriles transportaron las nuevas mercancías hacia los puertos de exportación.

27 VV.AA.: Problemas económicos de Honduras, Tegucigalpa, 1967, pág. 78. 
Desde del segundo quinquenio de la década del 70 se registró una tendencia inversa en el transporte ferroviario por causas ya señaladas, que favoreció a los demás medios de transporte competitivos con el ferrocarril. En la actualidad, el banano y la madera de exportación, y el trigo de importación son los principales productos que transportan los ferrocarriles hondureños. ${ }^{28}$

\section{Cuadro 12. TRANSPORTE DE MERCANCÍAS}

Quinquenio Tons. Tons. Tons./ Tons./km. Tons./km. Tons. $/ \mathrm{km}$.

\begin{tabular}{rrrcccc} 
& (miles) & hab. & km. vía & (millón) & hab. & /km. vía \\
\hline $1951-55$ & 1017 & 0,68 & 0,88 & 67 & 0,045 & 0,058 \\
$1956-60$ & 965 & 0,55 & 0,74 & 84 & 0,048 & 0,065 \\
$1961-65$ & 678 & 0,31 & 0,52 & 82 & 0,038 & 0,063 \\
$1966-70$ & 1408 & 0,57 & 1,08 & 38 & 0,015 & 0,029 \\
$1971-75$ & 2092 & 0,72 & 1,78 & 34 & 0,012 & 0,029 \\
$1976-80$ & 405 & 0,12 & 0,61 & 30 & 0,009 & 0,045 \\
$1981-85$ & 690 & 0,17 & 1,04 & 243 & 0,059 & 0,365 \\
$1986-90$ & 431 & 0,09 & 0,65 & 386 & 0,080 & 0,580
\end{tabular}

\section{El ferrocarril y el sistema de transporte}

Honduras es el país centroamericano que, por las particulares condiciones topográficas e históricas, posee el más deficiente sistema de vías de comunicación.

Las carreteras no significaron una verdadera competencia para el transporte ferroviario hasta finales de la década de 1950. Entre 1900 y 1948, las carreteras se construyeron a un promedio de $26 \mathrm{kms}$. por año, ${ }^{29}$ pero el principal producto de comercialización, el banano, tenía el fácil acceso de la vía marítima mediante la utilización exclusiva de los ferrocarriles que unían las zonas productoras con los puertos de exportación.

Desde mediados de siglo, nuevas áreas fueron abiertas a los cultivos comerciales; en el sur se inició el cultivo de café y algodón, se intensificó el comercio de carnes en la región de Olancho, y la madera comenzó a con-

28 INECO: Estudios ..., pág. 15.

29 VV.AA.: Problemas ..., pág. 84. 
siderarse como un nuevo producto de exportación. Fue necesaria, pues, la construcción de vías de comunicación para facilitar la movilización de los productos procedentes de aquellas regiones por donde no pasaba el ferrocarril. Desde 1948 a 1963 se construyeron nuevas carreteras a un promedio de $114 \mathrm{kms}$. por año, ${ }^{30}$ mientras otras eran reparadas para ofrecer un mejor servicio.

Para 1964, Honduras tenía $3.883 \mathrm{kms}$. de carreteras, aunque sólo un $10 \%$ estaba pavimentado; en la actualidad la red vial tiene aproximadamente $17.000 \mathrm{kms} .{ }^{31}$ pero con demasiadas deficiencias. La mayoría de las carreteras fueron construidas siguiendo rutas preexistentes, lo que determinó su mal trazado desde el punto de vista del transporte nacional y contribuyó a acentuar la autosuficiencia de las regiones y la desarticulación de las zonas productoras entre sí. Apenas 2.000 kms. de carretera están pavimentados; entre ellas cabe mencionar la Carretera Panamericana, que tiene fundamental importancia para el comercio con los restantes países centroamericanos..$^{32}$ La Carretera Interoceánica es otra vía de comunicación prioritaria para el país que ofreció una seria competencia al Ferrocarril Nacional ya que su trazado, a través de la depresión central, fue considerado en el siglo XIX como el adecuado para el Ferrocarril transístmico. Su extensión es de 355 kms. y enlaza Puerto Cortés con Amapala, a través de San Pedro Sula, Comayagua y Tegucigalpa. Otras vías terrestres son las que unen San Pedro Sula con Copán y Tegucigalpa con el Departamento de Olancho.

Al carecer Honduras de una red ferroviaria o vial útil y en buenas condiciones, el tráfico aéreo ofreció una alternativa. Tegucigalpa, San Pedro Sula y La Ceiba son aeropuertos internacionales. La red nacional de aeródromos está localizada en la zona norte de Honduras en una relación muy estrecha con las plantaciones de la zona, destacando los de Roatán - Islas de la Bahía-, Guanaja, Trujillo, Coyoles Central y Puerto Lempira. ${ }^{33}$

Honduras tiene un extenso litoral marítimo en la costa norte donde se concentran los puertos más importantes del país. Puerto Cortés es el más moderno, y uno de los mejores de América Central, y absorbe más del 50\% del tráfico marítimo de Honduras. Desde allí las mercancías tienen fácil acceso a través de la Carretera Interoceánica que une los principales cen-

30 Ibídem.

31 Pineda Portillo, Noé y Luzón Benedicto, José Luis: Honduras, Madrid, 1988, pág. 109.

32 CEPAL: El transporte en el Istmo centroamericano, México, 1983, pág. 60.

33 Pineda Portillo, N. y Luzón Benedicto, J. L.: Honduras ..., pág. 110. 
tros urbanos de la depresión central. Otros puertos importantes de la costa Atlántica son Tela, La Ceiba, destinados a la exportación de bananas y, recientemente, Puerto Castilla. En el sur, el tradicional puerto de Amapala cedió su importancia al de Henecán.

Antes de la inutilización de las vías del ferrocarril de la Standard Co., tanto el puerto de Tela como La Ceiba tenían un hinterland restringido y delimitado, ya que las vías férreas, únicas de acceso a los puertos, no estaban comunicadas con otras vías que penetrasen al interior del país. ${ }^{34}$ En la actualidad, sólo el puerto de Tela disfruta de esa condición. Puerto Cortés tiene un hinterland que se extiende hasta la capital del país al estar unido a San Pedro Sula y Potrerillos por vía férrea o carretera y desde allí, por carretera únicamente, hasta Tegucigalpa.

\section{Contribución del ferrocarril al desarrollo económico}

Si a mediados del siglo XIX la funcionalidad del proyectado ferrocarril en Honduras no era otra que la de un medio de rápida comunicación interocéanica para el beneficio de los intereses norteamericanos vinculados al negocio del oro californiano, desde comienzos del presente siglo, el ferrocarril fue construido acorde con nuevas aspiraciones de rentabililidad económica extranjera en el país. La creciente demanda internacional de racimos de banano y la desestructurada economía hondureña, con pocas vinculaciones al comercio exterior, propiciaron el desplazamiento de los productores locales del fruto y la rápida ocupación de compañías de origen norteamericano en la región norte del país. El acelerado desarrollo de la industria bananera no hubiese sido posible sin aquellos ferrocarriles "concedidos", ya que fueron los principales medios de transporte que posibilitaron la exportación del fruto hacia los mercados extranjeros.

Los ferrocarriles también supusieron una mayor dinámica social debido al desarrollo de importantes ciudades que trajo aparejado el negocio bananero, como La Ceiba, Tela, La Lima, San Pedro Sula y Puerto Cortés. Sin embargo, los ferrocarriles han contribuido muy poco al desarrollo económico de Honduras en términos nacionales. A pesar de que algunas regiones del país experimentaron un apreciado progreso a partir de la construcción ferroviaria, el mismo es más bien ficticio, porque más

34 CEPAL: El transporte ..., pág. 57. 
que integrar las potenciales zonas productoras del país, coadyuvó al funcionamiento y consolidación de la economía de enclave. ${ }^{35}$ La historia del ferrocarril en Honduras se confunde así con las propias fluctuaciones del capital extranacional.

Es difícil, por tanto, hablar en Honduras de una "red ferroviaria nacional". Desde comienzos del siglo XX hasta hace escasos años, más del $80 \%$ de los ferrocarriles eran propiedad de las compañías bananeras, de ahí que la rentabilidad de su explotación no se utilizara para activar procesos de acumulación económica en el país. El ferrocarril público, cuya construcción asumió el débil e invertebrado estado hondureño, no escapó del ritmo marcado por el negocio bananero. El costoso Ferrocarril Nacional, que fue completado apenas en su tercera parte del proyecto original, siempre se mantuvo por detrás de los ferrocarriles privados en cuanto a infraestructura y equipos de transporte. El peso económico que significó al estado el mantenimiento del ferrocarril fue de tal magnitud que, primero en 1920 y después en 1935 (y hasta 1958), se cedió su administración a compañías bananeras.

Durante toda la década de 1960 y principios de los 70, el conjunto de los ferrocarriles hondureños emprendieron un proceso de modernización que se tradujo en la reparación de vías y adquisición de material tecnológico. Este proceso se inscribió en un proyecto más amplio destinado a fomentar la industria y el comercio hondureño en el marco del Mercado Común Centroamericano. No obstante, ante la incapacidad de un grupo local para impulsar decisiones económicas a nivel nacional, fueron los mismos agentes privados vinculados con el negocio bananero los que diversificaron las actividades productivas del país. En efecto, el propio desarrollo demográfico relacionado con la producción y comercialización del banano, propició el crecimiento de la demanda de bienes de consumo y duraderos. Por entonces, las propias compañías extendieron sus negocios e invirtieron el capital en aquellas industrias que demandaba el mercado interno hondureño. Importante crecimiento experimentó la industrialización de vidrio, el algodón, el cuero, la madera, bebidas y alimentación.

Si bien el ferrocarril no era por entonces el único medio de transporte, debido a la construcción de otras vías terrestres de comunicación, operó desde una doble perspectiva. Por un lado, generó las potencialidades para

35 Lainez, Vilma y Meza, Víctor: "El enclave bananero en la historia de Honduras", pág. 153 en Estudios Sociales Centroamericanos, Tomo II, n. ${ }^{\circ}$ 5, 1973, págs. 115-156. 
el crecimiento y consolidación de la economía de enclave, fortaleciendo los nexos de dependencia con el mercado mundial. Por otro, en combinación con el tráfico automotor y la aviación civil, aceleró la vinculación de un incipiente, pero deformado y regional, mercado interior.

En la actualidad, y debido a la incorporación de la línea ferroviaria de la antigua Standard Railway Co. al Ferrocarril Nacional de Honduras, la situación económica de los ferrocarriles hondureños es extremadamente crítica. El sector de La Ceiba fue cerrado al tráfico por la escasa demanda de su servicio, provocado por el desplazamiento de las actividades industriales a la región más oriental de la costa del país. No obstante, los gastos de explotación continúan siendo altos para este sector por el necesario mantenimiento del material y, sobre todo, por el elevado coste de personal para la operación que se está realizando. El sector del Valle de Sula, si bien respondió a los requerimientos de la incipiente industria de cemento que se está desarrollando en el centro hondureño, en los últimos años descendió su actividad en un $20 \%$. Los resultados de explotación ferroviaria son, por tanto, negativos y anualmente acumulativos. En 1989 los resultados económicos fueron de -3.678 lempiras, en 1990 los mismos alcanzaron -7.054 lempiras. ${ }^{36}$

En 1993 finalizó la concesión al Tela Railway Co. Si bien aún no se produjo su traspaso a la administración del Ferrocarril Nacional, porque los intereses bananeros de la United Fruit Co. gozan de buena salud en la región, es necesario un nuevo acuerdo sobre la base de un programa de reestructuración de todo el sistema de comunicaciones terrestres de Honduras. Deberían superarse, entonces, las dificultades topográficas y financieras, que condicionaron históricamente el desarrollo económico hondureño.

36 INECO: Estudio ..., pág. 19. 


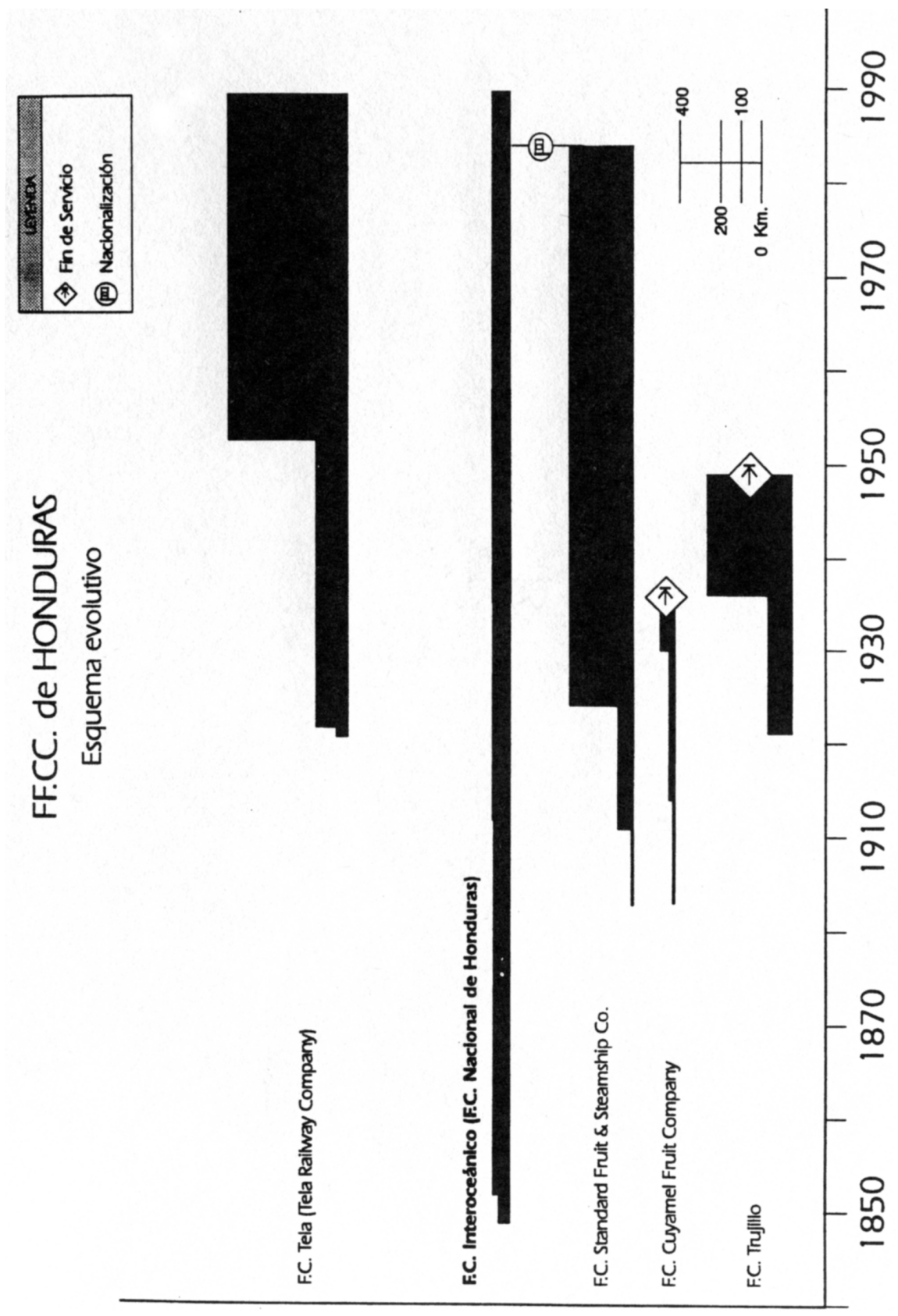

